\title{
Evaluation of changes in enamel thickness after orthodontic treatment depending on the force applied to remove orthodontic brackets: OCT analysis and universal testing machine
}

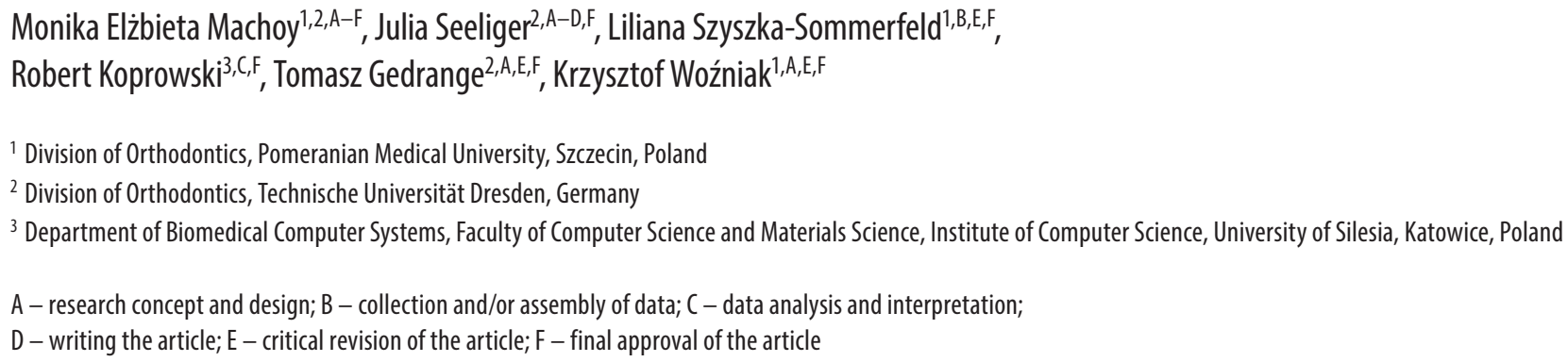

Address for correspondence

Monika Elżbieta Machoy

E-mail:m.machoy@gmail.com

Funding sources

None declared

Conflict of interest

None declared

Received on April 30, 2018

Reviewed on May 5, 2019

Accepted on August 9, 2018

Published online on March 19, 2019

Cite as

Machoy ME, Seeliger J, Szyszka-Sommerfeld L, Koprowski R, Gedrange T, Woźniak K. Evaluation of changes in enamel thickness after orthodontic treatment depending on the force applied to remove orthodontic brackets. OCT analysis and universal testing machine. Adv Clin Exp Med. 2019;28(6): 807-813. doi:10.17219/acem/94141

DOI

10.17219/acem/94141

Copyright

Copyright by Author(s)

This is an article distributed under the terms of the

Creative Commons Attribution Non-Commercial License

(http://creativecommons.org/licenses/by-nc-nd/4.0/)

\begin{abstract}
Background. Adhesive materials used in orthodontics have contributed to the broadening of treatment options with fixed braces. The adhesive materials physically and chemically bond to the enamel surface and orthodontic bracket base, which, apart from offering advantages, also entails the risk of enamel damage when removing these materials from the tissue surface after the treatment is complete.

Objectives. The objective of this study was to assess how the bond strength of adhesive materials affects enamel thickness after removing brackets and whether the type of bonding system affects the amount of adhesive strength of the discussed materials.

Material and methods. The tests were carried out on 2 groups of 40 bovine teeth in each group. In the $1^{\text {st }}$ group, the classical orthophosphoric acid and the Transbond Plus self-etching primer (SEP) were used. In the $2^{\text {nd }}$ group, the Transbond XT SEP was applied. In both groups, Transbond XT Light Cure Adhesive was used. The same metal orthodontic brackets were attached to the enamel surface. Optical Coherence Tomography (OCT) scans were made before and after removing brackets, which enabled tissue thickness measurements. The bond strength was evaluated using a universal testing machine. Parametric tests were performed on all obtained variables. Student's t-tests for independent samples and analysis of correlation with Pearson's r were carried out.
\end{abstract}

Results. The bond strength between the orthodontic bracket and enamel is statistically significantly different in the $1^{\text {st }}$ group and the $2^{\text {nd }}$ group, and is higher in the $2^{\text {nd }}$ group.

Conclusions. There are no significant differences in enamel thickness depending on the bonding system type and there is no correlation between the enamel thickness and the bond strength of orthodontic brackets to the enamel.

Key words: orthodontics, adhesives, enamel, optical coherence tomography, shear bond strength 


\section{Introduction}

The use of adhesive force in orthodontics may seem problematic due to the requirements specific to the field for which it is intended. When used in orthodontics, it should meet 2 requirements: be strong enough to support orthodontic brackets during the entire treatment, as well as resist the forces of chewing and tension caused by arches and the action and interference of patients. It should also be delicate enough to avoid enamel damage when removing brackets. ${ }^{1}$ This strength is due to the fact that the bonding material sticks to the irregularities of the enamel surface and the base of the attached element. These irregularities result from using etching techniques. The enamel pellicle is removed and the enamel hydroxyapatites and a small amount of the inter-prism substance are dissolved, which results in the formation of micropores with a depth from $5 \mu \mathrm{m}$ to $50 \mu \mathrm{m} .^{2}$ A $37 \%$ orthophosphoric acid solution is used for etching to condition enamel prior to the application of a composite material. The technique is based on the etching agent, adhesive system and composite material. To minimize the stages of attaching brackets, 3 separate elements were combined into 2 , having the properties of an etching agent and bonding system. ${ }^{3-5}$ Self-etching primers (SEP), due to the presence of an acidic primer, make it possible to exclude the use of an etchant agent. ${ }^{6}$ Electron microscope studies showed a similar enamel etching pattern of self-etching and classical systems. ${ }^{7}$ Self-etching primers exhibits a more classical etching pattern, ${ }^{8-10}$ while maintaining optimal bond strength. ${ }^{11}$ The adhesive strength of the self-etching system to the orthodontic brackets is from $20 \mathrm{MPa}$ to $30 \mathrm{MPa},{ }^{11}$ i.e., it shows a range similar to that of classical acid etching. ${ }^{12}$ The tests showed that the adhesive penetration range is smaller when using the self-etching system than normal etching. However, this is not a disadvantage, because the bigger the resin hooks in enamel, the greater the risk of its damage when removing brackets. ${ }^{13}$ The forces generated during bracket removal can depend on many factors: etching method, type of bonding system, orthodontic material, polymerization methods, and type and architecture of the bracket base. ${ }^{14,15}$ An increase in adhesive strength increases the risk of enamel damage. ${ }^{16}$ The tests presented in the article were carried out to check how bond strength affects enamel thickness after removing orthodontic brackets and whether the bonding system type affects the bond strength value.

\section{Material and methods}

\section{Preparing the teeth for the experiment}

The study was carried out in vitro on a group of 80 bovine teeth. The teeth were observed and selected in order to eliminate teeth with caries, cracks, hypomineralized enamel, or any other defects. The teeth were divided into
2 subgroups of 40 teeth each. The procedure of enamel etching was performed under laboratory conditions. In the $1^{\text {st }}$ subgroup, the classical method of enamel etching and the V generation bonding system (Transbond SEP Plus; $3 M$ Unitek, Monrovia, USA) were used. In the $2^{\text {nd }}$ subgroup, the VII generation (self-etching) bonding system (Transbond XT; 3M Unitek) was used. All procedures were performed by the same operator. Prior to the treatment, each tooth surface was cleaned and prepared with the Air-Flow ${ }^{\circledR}$ method (Clinpro Prophy Powder; 3M Espe AG, Seefeld, Germany), sprayed with water and dried with an air syringe for $15 \mathrm{~s}$. For fastening orthodontic brackets, an orthodontic composite material Transbond XT Light Cure Adhesive (3M Unitek) was used. In the $1^{\text {st }}$ group, the vestibular surface of the tooth was etched for $30 \mathrm{~s}$ with a $37 \%$ solution of phosphoric acid Blue-Etch (Cerkamed, Stalowa Wola, Poland), rinsed with distilled water for $15 \mathrm{~s}$ and dried using compressed air. The adhesive system Transbond SEP Plus was rubbed with an applicator into the etched enamel surface for $15 \mathrm{~s}$; then, the surface was dried under a gentle stream of air for $3 \mathrm{~s}$ and cured with a halogen lamp with light intensity of $750 \mathrm{~mW} / \mathrm{cm}^{2}$ for $20 \mathrm{~s}$. The orthodontic composite material Transbond XT Light Cure Adhesive was applied to the bracket surface. The bracket was pressed against the enamel surface with commonly used tweezers. The orthodontic bracket was placed in the middle of the mesial-distal axis of the tooth, moving its center $3.5 \mathrm{~mm}$ away from the edge of the occlusal surface. The distance was measured using an orthodontic positioner. After proper placement of the bracket, the material was subjected to polymerization with a halogen lamp for $40 \mathrm{~s}$.

In the $2^{\text {nd }}$ group, the self-etching adhesive system (Transbond XT) was used. The SEP, when applied to the tooth surface using an applicator, was left for $10 \mathrm{~s}$, and then the excess was removed with an air stream for $5 \mathrm{~s}$. After this time, the system was polymerized with a halogen lamp with light intensity of $750 \mathrm{~mW} / \mathrm{cm}^{2}$ for $20 \mathrm{~s}$. The orthodontic composite material Transbond XT Light Cure Adhesive was applied to the surface of the bracket. The orthodontic bracket was placed onto the tooth surface using the method described above.

\section{Analysis of the shear bond strength using a universal testing machine}

In order to insert a tooth in the appliance of the universal testing machine, a block in which the tooth had been embedded with an exposition of its labial surface was required. A silicone mold with cuboid shaped notches was produced (Fig. 1). One tooth was placed on a stick of wax and fixed into the notch with the labial surface upturned. The notch was filled up with autopolymerizable self-curing resin (SilaPress; Siladent Dr. Böhme \& Schöps GmbH, Goslar, Germany). Due to the objective of this study, evaluating the differences in the initial shear bond strength (SBS), no thermocycling or other aging procedures were 


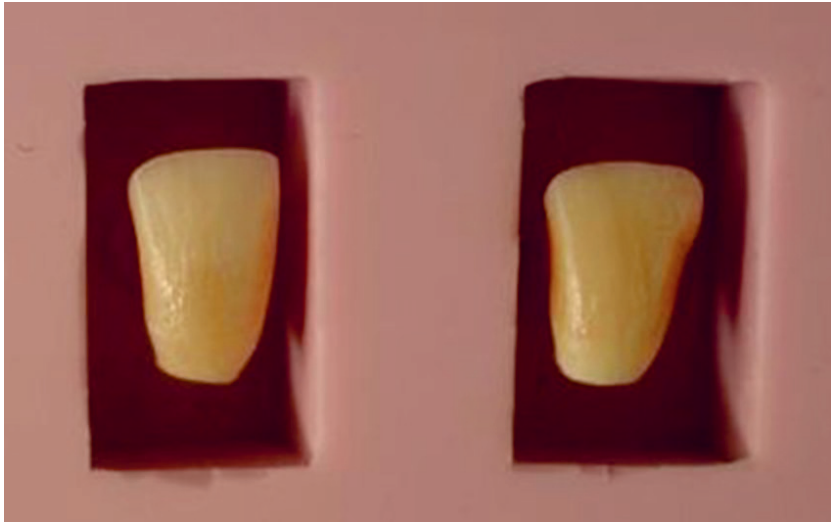

Fig. 1. Silicone mold used to create test blocks

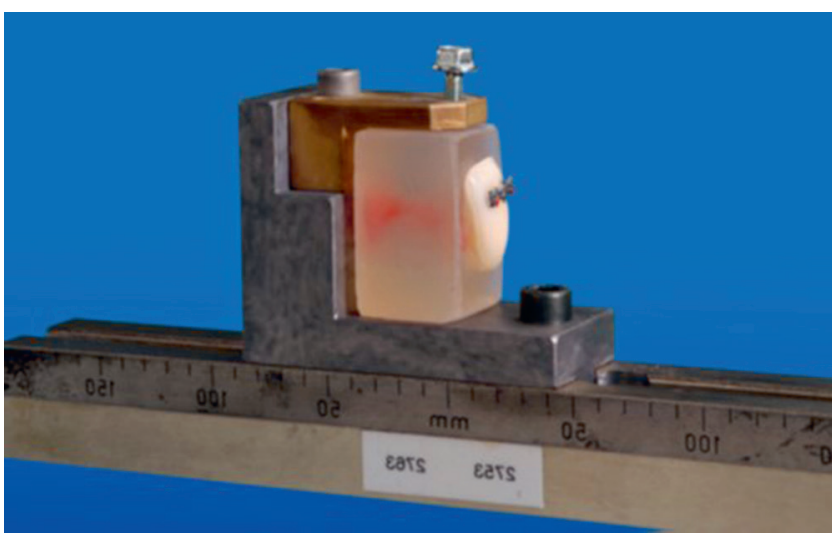

Fig. 2. Test block in the universal testing machine

accomplished. During the whole time, the teeth were stored in saline solution, with the addition of sodium azide $(50 \mathrm{mg} / \mathrm{L})$, until the time of the measurements. For measurements of the debonding force, the specimens were positioned in the universal testing machine (TIRAtest-2720, TIRA GmbH, Schalkau, Germany). The shear force was applied with a stainless steel rod parallel to the long axis of the tooth (Fig. 2, 3). A crosshead speed of $0.5 \mathrm{~mm} / \mathrm{min}$ was chosen. The SBS was recorded by dividing the numerical value $(\mathrm{N})$ of shear force by the base area $\left(\mathrm{mm}^{2}\right)$ of the bracket and converted to $\mathrm{MPa}$ in order to compare the measurements with those recorded in the literature.

\section{Analysis of enamel thickness using optical coherence tomography}

After the evaluation of SBS, the enamel was processed with the use of a micromotor mounted to a dental unit with a speed of 40,000 revolutions/min, water cooling and pressure force of $1.0 \mathrm{~N}$. The force was measured on a test stand consisting of scales, on which the processed tooth was placed. The procedure of cleaning the enamel was considered to be finished on the basis of the naked-eye examination and by touching with the stylet 23 in the dental unit light. The assessment criterion was the smoothness

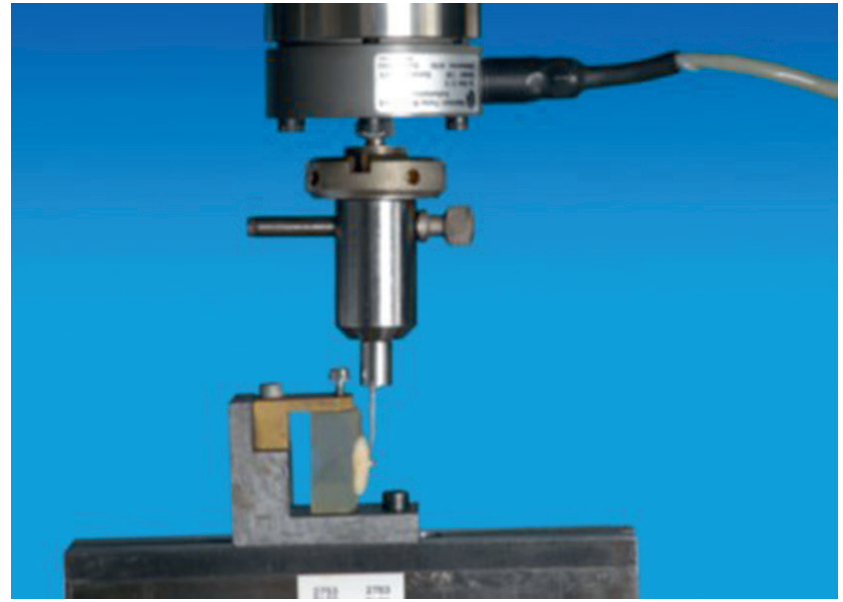

Fig. 3. Steel rod applying the shear force to the bracket from the occlusal surface

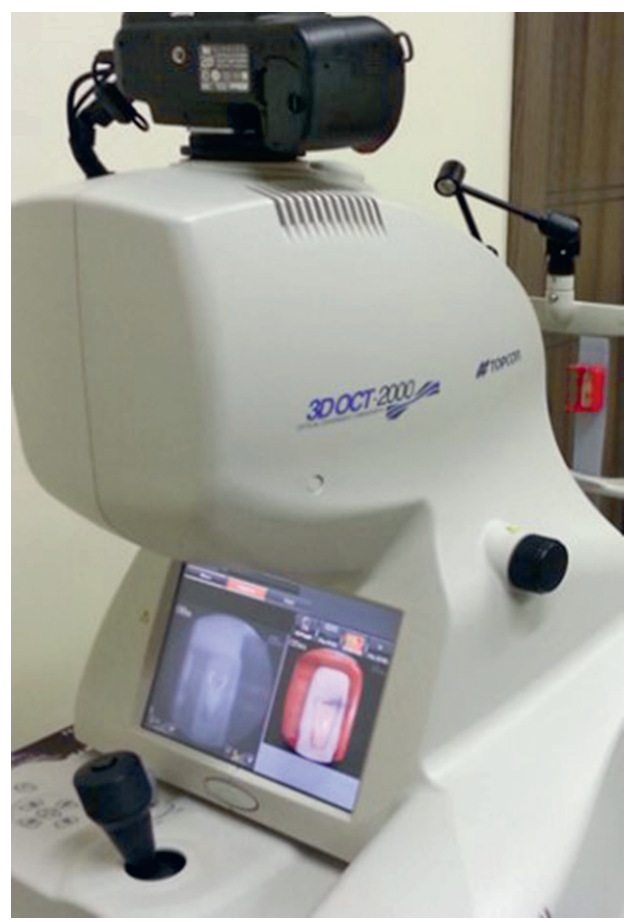

Fig. 4. Topcon 3D OCT-2000 used in the experiment

of the tooth surface and the absence of the composite material residues. The area of the test teeth was imaged with a 3D optical coherence tomography (OCT) camera (Topcon, Oakland, USA; Fig. 4) 2 times: imaging of the tooth surface before installing orthodontic brackets and after mechanical processing.

Each time, 2D scans were performed allowing for a clear illustration of the enamel damage in a vertical plane. The procedure made it possible to show the entire surface of the tissue and perform the subsequent comparative analysis of changes in its structure. It was possible to obtain accurate scans of the surface and enamel structure of teeth with due repeatability during 3 examinations, owing to the matrix described above. The matrix allowed for repeatable tooth 


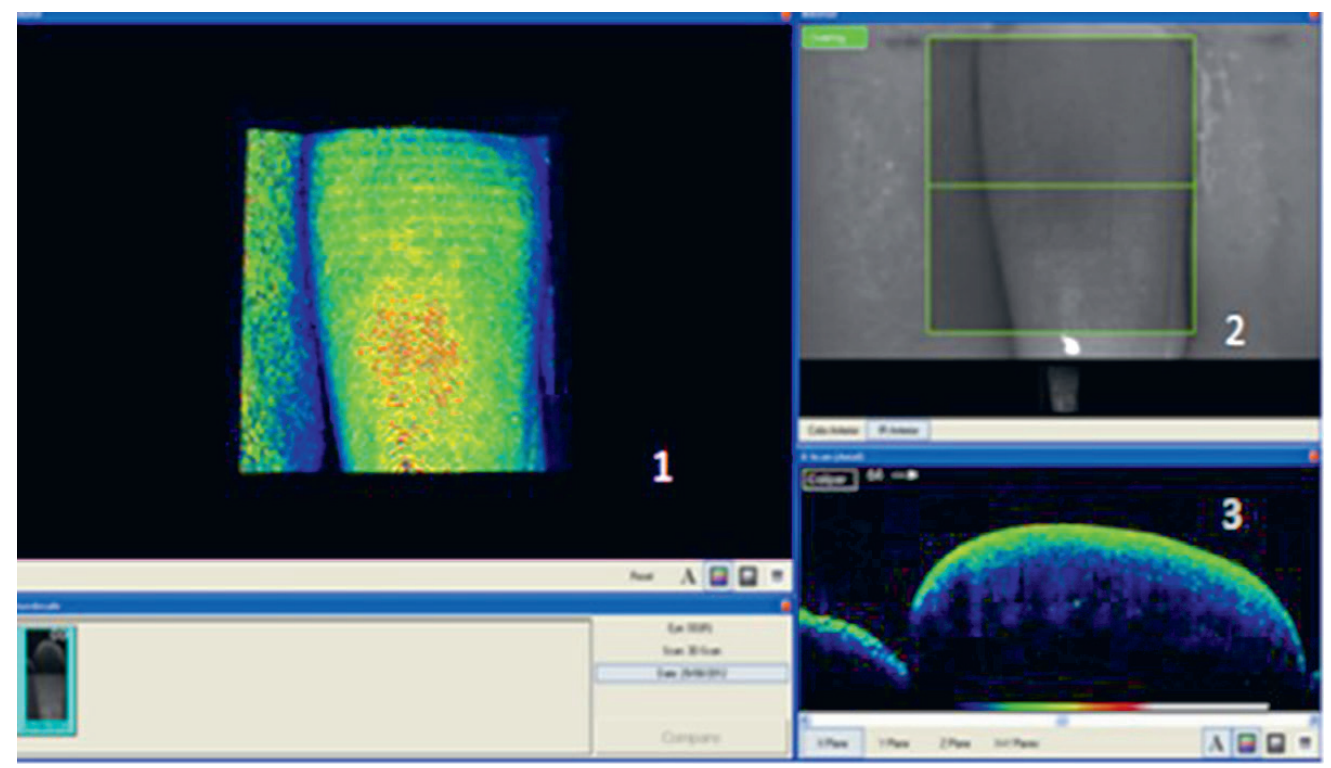

Fig. 5. Image on a computer screen after a tooth scan. 1) 3D image of the tooth surface. 2) A digital image of the picture taken using a coupled digital camera with a resolution of 16.2 Mpix. 3) An axial scan of the enamel tissue

positioning in the frontal, sagittal and horizontal planes relative to the optical axis of the OCT. The obtained scans were subjected to an expert IT analysis. Image pre-processing involved automatic reading of the order of OCT images from the source file with the extension ".fds, allowing for the development of matrices of individual images. Figure 5 shows the pictures and scans obtained using the tomography device. The IT analysis was described and published. ${ }^{17}$

\section{Statistical analysis}

IBM SPSS Statistics v. 24 software (IBM Corp., Armonk, USA) was used for statistical analysis. The basic descriptive statistics were calculated and the Kolmogorov-Smirnov test was performed to examine the normality of the distribution of 2 measured variables on a quantitative scale. Parametric tests were performed on all variables. Student's t-tests for independent samples and analysis of correlation with Pearson's $r$ were carried out. The threshold $\alpha=0.05$ was adopted as the level of significance.

In the first step, the basic descriptive statistics were calculated and the Kolmogorov-Smirnov test was performed, examining the normality of the distribution. In the course of the analysis, it was shown that the shape of enamel thickness distribution deviates significantly from the normal distribution. In turn, the distribution of bond strength is consistent with the normal distribution. The compared groups are of equal size and in the case of enamel thickness, the variances are homogeneous and the skewness of this variable does not exceed the absolute value equal to 1 . Therefore, analysis based on parametric tests was performed. The truthfulness of the obtained results in the Student's t-test was verified with the logarythmisation of the enamel thickness value and a simultaneous analysis was carried out on the transformed variable. The described results of basic descriptive statistics are presented in Table 1.

\section{Results}

\section{The effect of the adhesive system on enamel thickness and bond strength}

Comparisons of 2 groups were made using Student's t-test for independent samples. The obtained results, presented in Table 2, show that only bond strength is statistically

Table 1. Basic descriptive statistics and the result of the Kolmogorov-Smirnov test

\begin{tabular}{|l|c|c|c|c|c|c|c|c|c|}
\hline \multicolumn{1}{|c|}{ V generation adhesive system } & M & Me & SD & Sk & Kurt & Min & Max & K-S & p \\
\hline Bond strength & 14.33 & 14.35 & 1.22 & 0.23 & -0.87 & 12.20 & 16.90 & 0.11 & 0.200 \\
\hline Enamel thickness & 101.00 & 105.07 & 74.90 & 0.74 & 0.07 & 7.48 & 291.15 & 0.14 & 0.036 \\
\hline Enamel thickness (log) & 4.25 & 4.65 & 0.98 & -0.65 & -0.52 & 2.01 & 5.67 & 0.19 & 0.001 \\
\hline \multicolumn{1}{|c|}{ VIl generation adhesive system } & $\mathrm{M}$ & $\mathrm{Me}$ & $\mathrm{SD}$ & $\mathrm{Sk}$ & Kurt & Min & Max & K-S & $\mathrm{p}$ \\
\hline Bond strength & 16.97 & 16.90 & 0.85 & 0.30 & 0.47 & 14.90 & 19.00 & 0.14 & 0.060 \\
\hline Enamel thickness & 81.74 & 60.81 & 67.37 & 0.99 & -0.02 & 4.92 & 256.37 & 0.18 & 0.002 \\
\hline Enamel thickness (log) & 4.03 & 4.11 & 0.93 & -0.32 & -0.39 & 1.59 & 5.55 & 0.09 & 0.200 \\
\hline
\end{tabular}

M - mean; Me - median; SD - standard deviation; Min - minimum; Max - maximum; Sk - skewness; Kurt - kurtosis; K-S - result of the Kolmogorov-Smirnov test; $\mathrm{p}$ - significance of the distribution normality test. 
Table 2. Effect of the bonding system generation on bond strength and enamel thickness

\begin{tabular}{|c|c|c|c|c|c|c|c|c|c|}
\hline \multirow[t]{2}{*}{ Variables } & \multicolumn{2}{|c|}{$\begin{array}{l}\text { V generation bonding } \\
\text { system }(n=40)\end{array}$} & \multicolumn{2}{|c|}{$\begin{array}{l}\text { VII generation bonding } \\
\text { system }(n=40)\end{array}$} & \multirow[t]{2}{*}{$\mathrm{T}$} & \multirow[t]{2}{*}{$\mathrm{p}$} & \multicolumn{2}{|c|}{$95 \% \mathrm{Cl}$} & \multirow[t]{2}{*}{ Cohen's d } \\
\hline & M & SD & M & SD & & & LL & UL & \\
\hline Bond strength & 14.33 & 1.22 & 16.97 & 0.85 & -11.20 & $<0.001$ & -3.11 & -2.17 & 2.50 \\
\hline Enamel thickness & 101.00 & 74.90 & 81.74 & 67.37 & 1.21 & 0.230 & -12.45 & 50.98 & 0.27 \\
\hline Enamel thickness (log) & 4.25 & 0.98 & 4.03 & 0.93 & 1.01 & 0.316 & -0.21 & 0.64 & 0.23 \\
\hline
\end{tabular}

$\mathrm{n}$ - number of observations; M - mean; SD - standard deviation; $\mathrm{t}$ - Student's t-test results; $\mathrm{p}$ - significance; $95 \% \mathrm{Cl}$ - 95\% confidence interval for the difference between means; LL - lower limit of the Cl; UL - upper limit of the Cl.

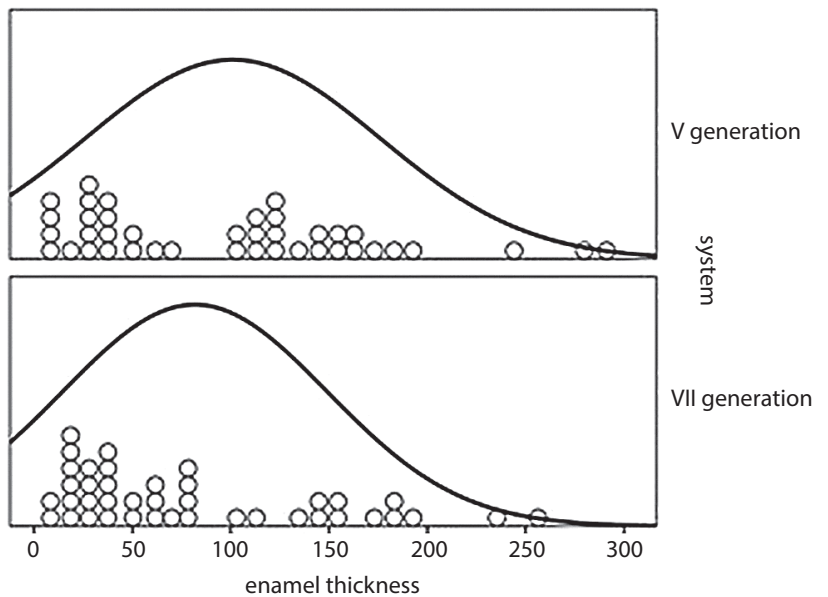

Fig. 6. Distribution of enamel thickness in the $\mathrm{V}$ and VII generation system groups

significantly differentiated between the 2 compared groups. The mean bond strength in the $\mathrm{V}$ generation system group was 14.33 MPa, whereas in the VII generation system group it was $16.97 \mathrm{MPa}$. The VII generation adhesive system is characterized by statistically significantly higher bond strength compared to the $\mathrm{V}$ generation system. In the case of enamel thickness, no significant differences are observed, both in the case of non-transformed and logged variables. The mean value of enamel thickness in the $V$ generation system group was $101.00 \mu \mathrm{m}$ and in the VII generation system group $-81.74 \mu \mathrm{m}$. The compared mean values together with the Student's t-test results are presented in Table 2. Figures 6 and 7 present the distribution of enamel thickness and bond strength in the $\mathrm{V}$ and VII generation system groups.

\section{Correlation between enamel thickness and bond strength}

A correlation analysis was performed in the 2 compared groups to check if enamel thickness correlates with bond strength. All correlation coefficients presented in Table 3 turned out to be statistically insignificant. Therefore, there are no grounds for rejecting the null hypothesis and concluding that bond strength affects enamel thickness. This result was obtained for both the V and VII generation bonding systems.

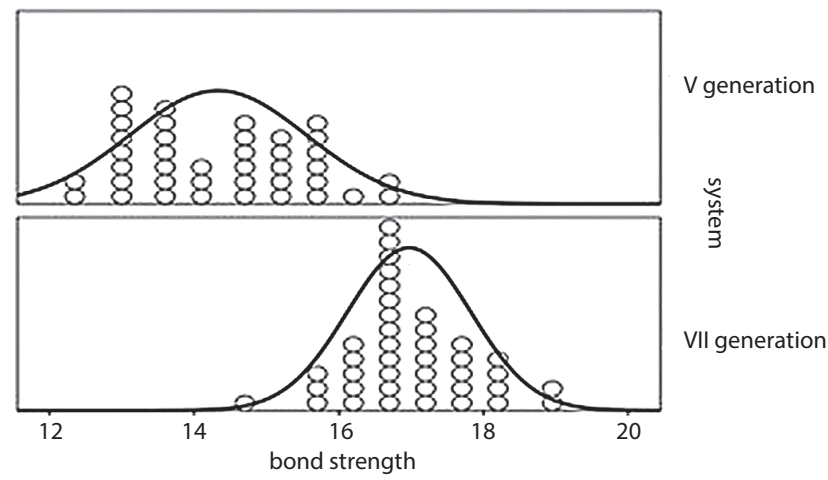

Fig. 7. Distribution of bond strength in the V and VII generation system groups

Table 3. Correlation between bond strength and enamel thickness

\begin{tabular}{|c|c|c|c|}
\hline Bonding system & Bond strength & Significance & Significance \\
\hline \multirow{4}{*}{$\begin{array}{l}V \text { generation } \\
\text { bonding system }\end{array}$} & \multirow{2}{*}{$\begin{array}{l}\text { enamel } \\
\text { thickness }\end{array}$} & Pearson's r & 0.118 \\
\hline & & $p$-value & 0.467 \\
\hline & \multirow{2}{*}{$\begin{array}{c}\text { enamel } \\
\text { thickness (log) }\end{array}$} & Pearson's r & 0.072 \\
\hline & & $p$-value & 0.657 \\
\hline \multirow{4}{*}{$\begin{array}{l}\text { VII generation } \\
\text { bonding system }\end{array}$} & \multirow{2}{*}{$\begin{array}{l}\text { enamel } \\
\text { thickness }\end{array}$} & Pearson's r & -0.172 \\
\hline & & $p$-value & 0.288 \\
\hline & \multirow{2}{*}{$\begin{array}{c}\text { enamel } \\
\text { thickness (log) }\end{array}$} & Pearson's r & -0.130 \\
\hline & & $p$-value & 0.424 \\
\hline
\end{tabular}

\section{Discussion}

In the presented experiment, the Transbond XT was used in both test groups. It has been used in many studies, ${ }^{18-21}$ so the results can be comparable. The bonding material Transbond SEP Plus has also been proven to be one of the best bonds used in orthodontics. The Transbond products are one of the few (next to the Clearfil SE) materials that show an acceptable stress behavior under the thermocycling conditions, which can mimic the in vivo conditions. ${ }^{20}$ Also, the risk of debonding-induced enamel defects is related to the bracket system used..$^{22}$ Therefore, only 1 bracket system has been used which was also used in earlier studies to get comparable results. ${ }^{23}$

The use of a conventional conditioning system requires an etching agent, which is based on $37 \%$ phosphoric acid. 
The SEP include phosphoric acid esters with an unknown, but probably lower concentration. The mode of etching and priming of the 2 bonding systems is different. In our research, the effect of the enamel etching method on its thickness after the completed treatment was evaluated. The studies evaluated the entire tissue subjected to etching, measuring the thickness of the cross-section from the inside to the outer border of the tissue, so it was possible to measure all the layers obtained with OCT imaging, which after their combination reflected the entire enamel cross-section. The mean enamel thickness after the completed treatment when using the classical etching method was $101.00 \mu \mathrm{m}$ and in the VII generation system group $-81.74 \mu \mathrm{m}$. However, the differences found were not statistically significant. The results show that enamel thickness after the treatment and its possible damage does not depend in any way on the bonding system type. The other authors' studies suggest a smaller effect of the self-etching system on the enamel, and our experiment leads to the conclusion that the effect of both systems on enamel is similar. The difference in results in this respect is due to the fact that the methodology of compared studies differs. Our own research focused on the quantitative evaluation of enamel, whereas previously presented experiments of other authors such as Retief, ${ }^{24}$ Arakawa et al., ${ }^{25}$ Asmussen, ${ }^{26}$ and Voss and Charbeneau ${ }^{27}$ assessed enamel qualitatively. They measured the amount of dissociated calcium and the depth of penetration of resin hooks. Therefore, it can be concluded that the results of the compared tests are not contradictory, as they measure different enamel features. The use of an etching agent does not reduce enamel thickness due to the lack of abrasive abilities. The etching method can only indirectly affect the final tissue thickness by significantly weakening its structure, which increases the enamel sensitivity to the operator's actions during the removal of brackets and cleaning process. The assessment of the full thickness of the tissue has been difficult so far, which is why there are not many publications that can be referred to when discussing our own results.

The next examined aspect was the bond strength of orthodontic brackets depending on the applied bonding system. In the reported results, the median SBS of the classical enamel etching method was $14.33 \mathrm{MPa}$, while in the VII generation system group it was 16.97 MPa. According to Reynolds, ${ }^{28}$ the minimum SBS of any adhesive for clinical use should lay between $5.88 \mathrm{MPa}$ and $7.84 \mathrm{MPa}$. The mean values of all tested primers-adhesive combination or systems showed suitable SBS values, far exceeding the minimum value. Retief $^{29}$ reported the incidence of enamel fractures in specimens with in vitro bond strength values of 9.7 $\mathrm{MPa}$. Even though the enamel can often withstand greater forces as indicated in the debonding force level reported, it is desirable to follow the instructions for debonding as recommended by the manufacturer to avoid enamel damage. ${ }^{30}$ In our results, the SBS in both groups was higher but the presented method was performed in vitro and the in vivo situation can be different. Limited access and poor direct sight may be a problem in the posterior teeth. According to Heravi et al., ${ }^{31}$ the SBS was below the clinically accepted values in most experimental groups. When light curing from the same side of the bracket is not possible, doubling the curing time and increasing the light intensity during trans-illumination are recommended for achieving acceptable bond strengths. Adhesion loss in the oral cavity can also be caused by thermal fluctuations and repetitive mechanical loads, fluid absorption, and biodegradation. ${ }^{32-35}$ Also, there was no correlation between SBS and enamel thickness. Many independent studies describe the features of selfetching systems, which include low aggressiveness in relation to the enamel. This causes significantly smaller, irreversible changes in the tissue compared to classical etching, and affects the production of shorter resin hooks. However, self-etching systems generate sufficient bond strength for the clinical procedure and fewer bonding errors in the enamel-bonding system phase than the classical etching method. ${ }^{36,37}$

\section{Conclusions}

The bond strength between the orthodontic bracket and enamel is statistically significantly different in the group of classical enamel etching method and the self-etching system group, and is higher in the $2^{\text {nd }}$ group. There are no significant differences in enamel thickness depending on the bonding system type. No correlation has been found between enamel thickness and bond strength of orthodontic brackets to enamel.

\section{References}

1. Powers JM, Messersmith ML. Enamel etching and bond strength. In: Brantley WA, Eliades T, eds. Orthodontic Materials: Scientific and Clinical Aspects. Stuttgart, Germany: Georg Thieme Verlag; 2001:105-122.

2. Øgaard B, Bishara SE, Duschner H. Enamel effects during bonding-debonding and treatment with fixed appliances. In: Graber TM, Eliades T, Athanasiou AE, eds. Risk Management in Orthodontics: Experts' Guide to Malpractice. Batavia, IL: Quintessence Publishing Co.; 2004:19-46.

3. Tay FR, Pashley DH. Aggressiveness of contemporary self-etching systems. Depth of penetration beyond dentin smear layers. Dent Mat. 2001;17(4):296-308.

4. Attar N, TanerTU, Tülümen E, Korkmaz Y. Shear bond strength of orthodontic brackets bonded using conventional vs one- and two step self-etching/adhesive systems. Angle Orthod. 2007;77(3):518-523.

5. Shinya M, Shinya A, Lassila LV, et al. Treated enamel surface patterns associated with five orthodontic adhesive systems: Surface morphology and shear bond strength. Dent Mat J. 2008;27(1):1-6.

6. Nishida K, Yamauchi J, Wada T, Hosoda H. Development of a new bonding system. J Dent Res. 1993;72:137.

7. Friedl $\mathrm{KH}$, Oberlander $\mathrm{H}, \mathrm{Schmalz} \mathrm{G}$, et al. Bond strength of composite resins using a new one-step adhesive system. J Dent Res. 2000;79: 33-36.

8. Hosein I, Sherriff M, Ireland AJ. Enamel loss during bonding, debonding, and cleanup with use of a self-etching primer. Am JOrthod Dentofacial Orthop. 2004;126(6):717-724. 
9. Horiuchi S, Kaneko K, Mori H, et al. Enamel bonding of self-etching and phosphoric acid-etching orthodontic adhesives in simulated clinical conditions: Debonding force and enamel surface. Dent Mat J. 2009;28(4):419-425.

10. Cal-Neto JP, Miguel JA. Scanning electron microscopy evaluation of the bonding mechanism of a self-etching primer on enamel. Angle Orthod. 2006;76(1):132-136.

11. Miyazaki M, Hirohata N, Takagaki K, et al. Influence of self-etching primer drying time on enamel bond strength of resin composites. J Dent. 1999;27(3):203-207.

12. Dorminey JC, Dunn WJ, Taloumis LJ. Shear bond strength of orthodontic brackets bonded with a modified 1-step etchant-and-primer technique. Am J Orthod Dentofacial Orthop. 2003;124(4):410-413.

13. Bishara SE, Von Wald L, Laffoon JF, et al. Effect of a self-etch primer/ adhesive on the shear bond strength of orthodontic brackets. Am J Orthod Dentofacial Orthop. 2001;119(6):621-624.

14. Ireland AJ, Hosein I, Sherriff M. Enamel loss at bond-up, debond and clean-up following the use of a conventional light-cured composite and a resin-modified glass polyalkenoate cement. Europ J Orthod. 2005;27(4):413-419.

15. Ozcan M, Finnema K, Ybema A. Evaluation of failure characteristics and bond strength after ceramic and polycarbonate bracket debonding. Europ J Orthod. 2008;30(2):176-182.

16. Ostman-Andersson E, Marcusson A, Hörstedt P. Comparative SEM studies of the enamel surface appearance following the use of glass ionomer cement and a diacrylate resin for bracket bonding. Swed Dent J. 1993;17(4):139-146.

17. Koprowski R, Machoy M, Woźniak K, Wróbel Z. Automatic method of analysis of OCT images in the assessment of the tooth enamel surface after orthodontic treatment with fixed braces. Biomed Eng Online. 2014;13:48.

18. Boruziniat A, Khazaei Y, Motaghi S, Moghaddas M. Evaluation of bond strength of orthodontic brackets without enamel etching. J Clin Exp Dent. 2015;7(4):519-523.

19. Brauchli L, Zeller M, Wichelhaus A. Shear bond strengths of seven self-etching primers after thermo-cycling. J Orof Orthop. 2011;72(5): 371-380.

20. Hellak A, Rusdea P, Schauseil M, Stein S. Enamel shear bond strength of two orthodontic self-etching bonding systems compared to Transbond ${ }^{\mathrm{TM}}$ XT. J Orof Orthop. 2016;77(6):391-399.

21. Menini A, Cozzani M, Sfondrini MF, Scribante A, Cozzani P, Gandini P. A 15-month evaluation of bond failures of orthodontic brackets bonded with direct versus indirect bonding technique: A clinical trial. Prog Orthod. 2014;15(1):1-6.
22. Zielinski V, Reimann S, Jager A, Bourauel C. Comparison of shear bond strength of plastic and ceramic brackets. J Orof Orthop. 2014;75(5): 345-357.

23. Richter C, Jost-Brinkmann PG. Shear bond strength of different adhesives tested in accordance with DIN 13990-1/-2 and using various methods of enamel conditioning. J Orof Orthop. 2015;76(2):175-187.

24. Retief $\mathrm{DH}$. Effect of conditioning the enamel with phosphoric acid. J Dent Res. 1973;52(2):333-341.

25. Arakawa $Y$, Takahashi $Y$, Sebata $M$. The effect of acid etching on the cervical region of the buccal surface the human premolar, with special reference to direct bonding techniques. Am J Orthod. 1979;76(2): 201-208.

26. Asmussen E. Penetration of restorative resins into acid etched enamel. Il. Dissolution of entrapped air in restorative resin monomers. Acta Odont Scand. 1977;35(4):183-191.

27. Voss JE, Charbeneau GT. A scanning electron microscope comparison of three methods of bonding resin to enamel rod ends and longitudinally cut enamel. J Am Dent Assoc. 1979;98(3):384-389.

28. Reynolds IR. A review of direct orthodontic bonding. Brit J Orthod. 1985;2:171-178.

29. Retief DH. Failure at the dental adhesive-etched enamel interface. J Oral Rehabil. 1974;1(3):265-284

30. Mundstock KS, Sadowsky PL, Lacefield W, Bae S. An in vitro evaluation of a metal reinforced orthodontic ceramic bracket. Am J Orthod Dentof Orthop. 1999;116(6):635-641.

31. Heravi F, Moazzami SM, Ghaffari N, Jalayer J, Bozorgnia Y. Evaluation of shear bond strength of orthodontic brackets using trans-illumination technique with different curing profiles of LED light-curing unit in posterior teeth. Prog Orthod. 2013;14:49.

32. Gwinnett AJ, Yu S. Effect of long-term water storage on dentin bonding. Am J Dent. 1995;8(2):109-111.

33. Kitsako Y, Burrow MF, Nikaido T, Tagami J. The influence of storage solution on dentin bond durability of resin cement. J Dent. 2000;16(1):1-6.

34. Murray SD, Hobson RS. Comparison of in vivo and in vitro shear bond strength. Am J Orthod Dentof Orthop. 2003;123(1):2-9.

35. lijima M, Ito S, Yuasa T, Muguruma T, Saito T, Mizoguchi I. Bond strength comparison and scanning electron microscopic evaluation of three orthodontic bonding systems. J Dent Mat. 2008;27(3):392-399.

36. de Oliveira $\mathrm{CH}$, da Silva AM, Briso AL, Briso AL, Sundfeld ML. Resin tag length of one-step and self-etching adhesives bonded to unground enamel. Bull Tokyo Dent Coll. 2005;46(3):43-49.

37. Bishara SE, Oonsombat C, Soliman MM, Warren JJ, Laffoon JF, Ajlouni R. Comparison of bonding time and shear bond strength between a conventional and a new integrated bonding system. Angle Orthod. 2005;75(2):237-242. 